\title{
Seguimiento clínico, serológico y mediante la reacción de polimerasa en cadena de una familia con brucelosis
}

\author{
M. Rosario Morales-García, Nayely García-Méndez, S. Diana Regalado-Jacobo, \\ Ahidé López-Merino y Araceli Contreras-Rodríguez
}

\section{Clinical, serological and polymerase chain reaction follow-up of a family with brucellosis}

Introduction: Human brucellosis diagnosis is based on isolation of Brucella spp. from blood or tissue cultures with a positivity rate of $40-70 \%$ and serology techniques are used as complementary tools; recently molecular biology diagnostic techniques have been developed intending to optimize the etiological confirmation. Aim: The main objective of this work was to compare the polymerase chain reaction (PCR), against serological diagnostic tests during the clinical follow-up of a family presenting brucellosis. Methods: Seven family members who lived in the urban area of Mexico City, were monitored using the Rose Bengal test, the agglutination test as well as agglutination with 2 mecapto ethanol, blood cultures and serum PCR for a period of 27 months. The suspected source of infection was fresh goat cheese from a known endemic zone. Results: Brucella melitensis was isolated from the blood cultures of two patients. All of the patients were positive in serological and PCR tests at the beginning of this follow-up. At the end of the study, three patients responded well to the treatment and showed negative results in the serological and PCR tests. While two patients with diabetes mellitus type 2, showed positive results in the serological and PCR tests as well as persistent symptoms. Conclusion: Clinical follow-up of patients with brucellosis is of great importance, to properly evaluate the given treatment. In this sense the PCR is a great supporting tool in diagnostic testing.

Key words: Brucellosis, fresh cheese, PCR, serology, Brucella.

Palabras clave: Brucelosis, queso fresco, RPC, serología, Brucella.

\section{Introducción}

\section{$\mathrm{L}$}

a brucelosis es una zoonosis de distribución mundial y endémica en varias regiones del mundo. La enfermedad afecta principalmente a la cuenca del Mediterráneo, Península Arábiga, México, Centro y Sudamérica $^{1}$. La susceptibilidad de los humanos a la bacteria depende del estatus inmunológico, la ruta de infección, del tamaño del inóculo, y de la virulencia de la bacteria. Las vías comunes de infección incluyen la inoculación directa a través de abrasiones de la piel, por inhalación de aerosoles, y la indirecta, a través de la ingesta de derivados lácteos crudos o no pasteurizados ${ }^{2}$. Brucella melitensis es la especie más frecuentemente reportada en los casos humanos, y también la más aislada de animales en los países endémicos; se asocia a cabras y borregos, aunque otros animales pueden ser susceptibles entre ellos perros, vacas, y camellos. En algunos países, particularmente del Medio Oriente y en España, se han reportado brotes en ganado vacuno por B. melitensis ${ }^{3,4}$. En este sentido, es importante tipificar la especie de Brucella causante de los brotes en animales para aplicar las medidas de control más adecuadas.
La brucelosis puede comprometer a cualquier órgano o tejido del cuerpo, y generar una serie de complicaciones; entre las más comunes, las osteo-articulares, gastrointestinales, hepato-biliares, vías respiratorias, genitourinarias, cardiovasculares, neurológicas, cutáneas, y oftálmicas. Usualmente se presenta como un cuadro febril agudo y puede afectar a cualquier grupo de edad. La enfermedad puede persistir y manifestarse como una recaída o progresar a una infección crónica localizada ${ }^{5}$. Y aunque los anticuerpos juegan un papel en la resistencia a la infección, el principal mecanismo de eliminación de la bacteria es a través de una respuesta inmunológica celular ${ }^{6}$. Debido a que la manifestación clínica de la brucelosis es inespecífica, puede llegar a confundirse con otras enfermedades febriles; en tal caso el tratamiento será inadecuado ${ }^{7}$. El aislamiento del patógeno se considera la prueba de oro en el diagnóstico. Sin embargo, debido a que Brucella es un microorganismo de lento crecimiento y a que el porcentaje de aislamiento varía entre 40 y $70 \%$, las pruebas serológicas son las más usadas en el establecimiento del diagnóstico de brucelosis en humanos ${ }^{7,8}$. En los últimos años la reacción de polimerasa en cadena (RPC) también se ha utilizado en el diagnóstico de brucelosis en
Instituto Politécnico Nacional. México, D.F. México. Escuela Nacional de Ciencias Biológicas. Departamento de Microbiología (MRM-G, SDR-J, AL-M, AC-R).

Universidad Nacional Autónoma de México. México D.F. México. Facultad de Medicina (NG-M).

Los autores declaran no tener conflictos de interés.

Este trabajo fue apoyado por proyectos CONACYT 76395 , 169259, SIP-IPN 20131610, ICYTDF-IPN.

Recibido: 10 de noviembre de 2013 Aceptado: 11 de marzo de 2014

Correspondencia a: Araceli Contreras-Rodríguez aracelicontreras21@gmail.com 
diferentes muestras clínicas, utilizando diferentes genes específicos para la identificación de Brucella a nivel de género y especie ${ }^{9-11}$.

En este trabajo realizamos el seguimiento clínico de siete integrantes de una familia con brucelosis que vivía en la zona urbana de la Ciudad de México. Efectuamos pruebas serológicas, detección de la bacteria en sangre y la RPC durante 27 meses. Durante el seguimiento se documentó el tratamiento, cuya eficacia fue evaluada mediante las pruebas de diagnóstico y el estado clínico de cada paciente. Además, discutimos la respuesta terapéutica de dos pacientes diabéticas con brucelosis.

\section{Material y Métodos}

El presente es un estudio descriptivo sobre casos de personas con brucelosis en la zona urbana de la Ciudad de México desde enero de 2011 hasta marzo de 2013.

\section{Descripción de los pacientes}

El seguimiento clínico se hizo a siete integrantes de una familia con brucelosis, quienes firmaron un consentimiento de información para participar en este trabajo, de acuerdo al protocolo MIC/ENCB/4265/2011 aprobado por el Comité Ético Científico ad hoc de la Escuela Nacional de Ciencias Biológicas del Instituto Politécnico Nacional. El período de seguimiento fue a $\operatorname{los} 3,6,9,12,15,18$, 21, 24 y 27 meses posteriores al diagnóstico inicial de brucelosis en enero de 2011. Durante este período se realizaron: detección de la bacteria en sangre, pruebas serológicas, RPC en el suero, registro de la sintomatología y tratamiento. Se obtuvieron hemocultivos al inicio, a los seis y nueve meses a todos los pacientes. Los aislados de Brucella spp. obtenidos de los hemocultivos se tipificaron mediante criterios microbiológicos y por biología molecular.

\section{Datos epidemiológicos}

Los pacientes fueron diagnosticados inicialmente con otros padecimientos febriles: el caso índice y la abuela como casos de salmonelosis; el padre de familia, la tía, la prima y el hermano fueron diagnosticados y manejados como faringitis aguda; mientras que la madre de familia fue inicialmente manejada como un cuadro de infección de vías urinarias y posteriormente como salmonelosis. Todos ellos vivían en la zona urbana de la Ciudad de México, sin contacto con animales de granja. Una vez que el caso índice fue reconocido como brucelosis, se hizo una encuesta a cada miembro de la familia y se reveló que la abuela paterna en el mes de septiembre de 2010 había visitado a familiares en el Estado de Guanajuato, México. Guanajuato se localiza a $300 \mathrm{~km}$ de Ciudad de México, donde es tradicional la elaboración de productos lácteos, en especial los quesos de cabra. En esa visita la abuela compró quesos frescos que llevó a la Ciudad de México y los compartió con la familia.

\section{Caso índice}

A finales de noviembre de 2010 una joven de 19 años presentó cefalea, astenia y adinamia, fiebre de predominio vespertino y vértigo, pero no acudió a facultativo ni hubo medicación. Un mes después, al continuar con la sintomatología, acudió a los servicios médicos escolares de su Universidad en Ciudad de México donde se le diagnosticó salmonelosis y recibió tratamiento con metronidazol 500 $\mathrm{mg} / 12 \mathrm{~h}$ /durante siete días. En enero de 2011, al seguir con fiebre y cefalea, acudió al laboratorio de Microbiología Especializada de su Universidad y bajo la sospecha de una infección por Brucella spp. se le realizaron las pruebas serológicas de aglutinación con el antígeno Rosa de Bengala y prueba de aglutinación en suero (SAT) y en presencia de 2-mercapto etanol (2ME). Los resultados mostraron aglutinación positiva con el antígeno Rosa de Bengala, y títulos 1:320 en SAT y 1:160 en 2ME.

\section{Tratamiento}

Durante el seguimiento, los pacientes recibieron diferentes tratamientos llevados a cabo por el personal médico de su Clínica de Atención Familiar del Instituto Mexicano del Seguro Social (IMSS) y de acuerdo a la Norma Oficial Mexicana: Para la Prevención y Control de la Brucelosis en el Hombre, en el Primer Nivel de Atención. (NOM 022-SSA2- 2012).

Tratamiento A: cotrimoxazol (320/1.600 mg/día (5 $\mathrm{mg} / \mathrm{kg} /$ día- $25 \mathrm{mg} / \mathrm{kg} /$ día) por vía oral (V.O) y rifampicina $600-900 \mathrm{mg} /$ día $(20 \mathrm{mg} / \mathrm{kg} /$ día $)$ V.O. Tratamiento $\mathrm{B}$ : doxiciclina $100-200 \mathrm{mg} /$ día (3 mg/kg/día) V.O y rifampicina $600-900 \mathrm{mg} /$ día $(20 \mathrm{mg} / \mathrm{kg} /$ día $)$ V.O. Tratamiento C: estreptomicina $1.000 \mathrm{mg} /$ día $(14 \mathrm{mg} / \mathrm{kg} /$ día $)$ por vía intramuscular (I.M) y tetraciclina $2.000 \mathrm{mg} /$ día $(25 \mathrm{mg}$ $/ \mathrm{kg} /$ día) V.O ${ }^{12}$.

\section{Pruebas serológicas}

Prueba de Rosa de Bengala (RB). El antígeno Rosa de Bengala consiste de una suspensión de Brucella (al 8\%) y teñidascon el colorante Rosa de Bengala en un tampón con $\mathrm{pH} 3,65 \pm 0,05$. Esta es una prueba de aglutinación que consiste poner en contacto suero del paciente y el antígeno en una placa de aglutinación. Una reacción positiva se observa con la aparición de grumos rosas, con un fondo transparente. Se le considera una prueba de tamizaje, barata, rápida, y específica que detecta anticuerpos aglutinantes IgM e IgG1 ${ }^{13}$.

Prueba de aglutinación (SAT). En esta prueba (por sus siglas en inglés: serum agglutination test), el antígeno consiste de una suspensión de células de $B$. abortus cepa 1119-3 muertas por fenol. Se hacen diluciones seriadas 
del suero en solución salina y se adiciona el antígeno; la prueba positiva se observa con la presencia de una malla de aglutinación en el fondo del tubo (o en los pozos de una microplaca, cuando se usa el micrométodo) y el sobrenadante transparente. Detecta los anticuerpos aglutinantes $\operatorname{IgM}$, IgG e $\operatorname{IgA}^{13}$ y se le considera positiva con títulos $\geq 1: 80^{12}$.

Prueba de aglutinación en presencia de 2-mercapto etanol. En este caso se usa el mismo antígeno que en la prueba SAT; la única variante es la adición de 2-mercapto etanol (2-ME) en la solución salina con la que se diluye el suero. El 2-ME, al ser un agente reductor, rompe los enlaces disulfuro y despolimeriza al pentámero de la IgM

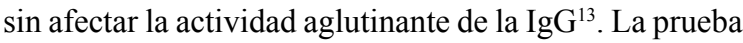
se considera positiva con títulos $\geq 1: 20^{12}$.

Hemocultivo e identificación microbiológica de los aislados de Brucella. La muestra de siete $\mathrm{mL}$ de sangre se obtuvo por venopunción que fue inoculada en frascos con medio bifásico Ruiz-Castañeda. Los frascos de hemocultivo se incubaron a $37^{\circ} \mathrm{C}$ y se examinaron diariamente durante 30 días; $0,5 \mathrm{~mL}$ del medio líquido del hemocultivo se sembró en cajas de agar de soya y tripticaseína e incubado en $5 \%$ de $\mathrm{CO}_{2}$. Las colonias con morfología colonial semejante a Brucella fueron identificadas mediante la tinción de Gram, oxidasa, catalasa, producción de ureasa, ácido sulfhídrico, sensibilidad a fucsina, tionina, susceptibilidad a fagos, y a la aglutinación con sueros monoespecíficos ${ }^{13,14}$.

Diagnóstico molecular de Brucella spp. en muestras de suero de los pacientes. La identificación molecular de Brucella spp., en el suero de los pacientes, se llevó a cabo mediante la amplificación de una región conservada del gen que codifica para una proteína de membrana de $31 \mathrm{kDa}(\mathrm{BCSP} 31)$ y con un producto esperado de 223 pares de bases ( $\mathrm{pb}$ ) específico del género Brucella $^{15}$. Este ensayo de RPC propuesto por Baily y cols., en 1992, se ha aplicado y validado en suero y sangre periférica humana en laboratorios de diferentes países, mostrando mejor sensibilidad en suero ${ }^{16}$. Para evaluar la especificidad de la prueba de RPC se incluyeron dos grupos: 15 donantes sanos y 15 pacientes que presentaron infección gastrointestinal (que fueron negativos a las pruebas serológicas de Brucella).

Tipificación molecular de los aislados de Brucella mediante RPC multiplex. La identificación molecular de los aislados de Brucella se basó en el ensayo de RPC multiplex Bruce-Ladder ${ }^{17}$. Este ensayo propuesto por García-Yoldi y cols., en 2006, que permite la identificación de las especies de Brucella y cepas vacunales en una sola reacción se ha validado con aislados de Brucella de diferentes países ${ }^{18}$.

En los ensayos de RPC se extrajo ADN de las siguientes cepas de referencia que fueron utilizadas como testigo positivo de reacción: B. abortus ATTC 23448 (544), B. melitensis bv 1 ATTC $23456(16 \mathrm{M})$ y B. suis bv 1 ATCC 23444 (1330). Como testigo negativo se usó ADN de Escherichia coli ATCC 25922.

Extracción de ADN de suero de pacientes y de los aislados de Brucella. La extracción de ADN de las cepas aisladas, así como del suero de los pacientes, de los donantes sanos y de los pacientes con infección gastrointestinal, se realizó mediante el método de $\mathrm{CTAB}^{18}$.

\section{Resultados}

La Tabla 1 resume los datos de identificación de cada uno de los pacientes, su sintomatología y la duración del cuadro clínico. Los síntomas más frecuentes fueron: fiebre vespertina, pérdida de peso, astenia, adinamia y artralgias. La edad de los pacientes osciló entre 19 y 76 años.

Los resultados de las pruebas aplicadas a cada paciente se muestran en la Tabla 2. Al inicio del seguimiento todos los pacientes mostraron serología positiva, RPC positiva. El aislamiento de $B$. melitensis bv 1 a partir de los hemocultivos, fue positivo solamente en las muestras del padre y del hermano obtenidas al inicio del seguimiento.

En la Figura 1 se muestra el producto de amplificación de 223 pb del gen que codifica para la proteína BCSP31 específica del género Brucella en las muestras de suero de todos los pacientes, al inicio del seguimiento. El ensayo de RPC se hizo en todas las muestras de los sueros de los pacientes a lo largo de todo el seguimiento (Tabla 2). Los sueros de los voluntarios sanos y de los pacientes con infección gastrointestinal fueron negativos a la prueba de RPC (datos no mostrados).

En la Figura 2 podemos observar el perfil de amplificación obtenido en la RPC multiplex de los dos aislados de los hemocultivos de los pacientes. Los aislados se identificaron como B. melitensis, ya que mostraron productos de amplificación de 152, 450, 587, 794, $1.071 \mathrm{y}$ $1.682 \mathrm{pb}$ que permitieron diferenciarlos de B. abortus 544 y B. suis 1330 . Por medio de las pruebas microbiológicas se identificó la biovariedad 1.

En el caso índice, a los seis meses del término del tratamiento con cotrimoxazol y rifampicina, sus títulos de anticuerpos anti-Brucella fueron 1:160 en SAT, 1:80 en 2 ME y RPC positiva. La paciente decidió no tomar tratamiento alguno posteriormente, a pesar de continuar con cefaleas, artralgias, astenia y adinamia.

El padre, la tía y la prima recibieron el tratamiento de cotrimoxazol y rifampicina durante 21 días; sin embargo, a los dos meses de terminado el tratamiento, continuaban con síntomas y sus títulos no habían disminuido. Los tres pacientes tomaron un segundo tratamiento a los seis meses del seguimiento, doxiciclina y rifampicina durante seis semanas. Después de seis meses de haber concluido 
Tabla 1. Datos epidemiológicos al inicio y al final del seguimiento de la familia con brucelosis

\begin{tabular}{|c|c|c|c|c|c|c|}
\hline Paciente & $\begin{array}{c}\text { Edad/ } \\
\text { sexo }\end{array}$ & Ocupación & $\begin{array}{l}\text { Fecha probable de } \\
\text { infección de }\end{array}$ & $\begin{array}{c}\text { Desarrollo de } \\
\text { sintomatología previo al } \\
\text { diagnóstico correcto de } \\
\text { brucelosis (meses) }\end{array}$ & Sintomatología & $\begin{array}{l}\text { Gravedad del caso al final } \\
\text { del seguimiento }\end{array}$ \\
\hline Caso índice & $19 / F$ & Estudiante & Septiembre-octubre 2010 & 2 & $\begin{array}{l}\text { Fiebre vespertina, náuseas, debilidad, } \\
\text { sudoración y pérdida de peso }\end{array}$ & $\begin{array}{l}\text { Continúa con cefaleas, } \\
\text { artralgias, astenia y adinamia }\end{array}$ \\
\hline Padre & $52 / \mathrm{M}$ & Taxista & Septiembre-octubre 2010 & 2 & $\begin{array}{l}\text { Fiebre vespertina, náuseas, debilidad, } \\
\text { sudoración y pérdida de peso }\end{array}$ & Ninguno \\
\hline Tía & $38 / F$ & Enfermera & Septiembre-octubre 2010 & 2 & $\begin{array}{l}\text { Fiebre vespertina, náuseas, debilidad, } \\
\text { sudoración y pérdida de peso }\end{array}$ & Ninguno \\
\hline Prima & $26 / F$ & Comerciante & Septiembre-octubre 2010 & 2 & $\begin{array}{l}\text { Fiebre vespertina, náuseas, debilidad, } \\
\text { sudoración y pérdida de peso }\end{array}$ & Ninguno \\
\hline Madre & $49 / F$ & Hogar & Septiembre-octubre 2010 & 2 & $\begin{array}{l}\text { Fiebre vespertina, náuseas, debilidad, } \\
\text { sudoración y pérdida de peso }\end{array}$ & $\begin{array}{l}\text { Artralgia, cefalea, consunción } \\
\text { crónica }\end{array}$ \\
\hline Abuela & $76 / F$ & Hogar & Septiembre-octubre 2010 & 2 & $\begin{array}{l}\text { Fiebre vespertina, náuseas, debilidad, } \\
\text { sudoración y pérdida de peso }\end{array}$ & $\begin{array}{l}\text { Coxartrosis en cadera, } \\
\text { imposibilidad para la marcha }\end{array}$ \\
\hline Hermano & $28 / \mathrm{M}$ & Empleado & Septiembre-octubre 2010 & 2 & $\begin{array}{l}\text { Pérdida de peso, cefalea y sudoración } \\
\text { vespertina }\end{array}$ & Continúa con vértigo, cefalea \\
\hline
\end{tabular}

\section{Tabla 2. Resultados de serología, RPC y aislamiento de Brucella melitensis bv 1 durante el tratamiento de una familia con brucelosis}

Paciente

1 Caso índice

Padre

Tía

4 Prima

5 Madre

(1)

6 Abuela

2

7 Hermano

$\begin{array}{ll}\text { RPC } & \\ \text { SAT } & 1: \\ \text { 2ME } & 1: \\ \text { RB } & \end{array}$

\section{0}

$+$

$1: 320$

160

$+$

RPC

SAT $1: 640$

2ME

$\mathrm{RB}$

$1: 320$

$+{ }^{*}$

RPC

SAT

2ME

$\mathrm{RB}$

RPC

SAT

2ME

$\mathrm{RB}$

RPC

SAT $\quad 1: 640$

2ME $\quad 1: 320$

$\mathrm{RB}$

RPC

2ME

$\mathrm{RB}$

RPC

SAT

2ME

$\mathrm{RB}$

$1: 320$

+
+

$1: 320$

$1: 160$

$+$

$+$

3

$\begin{array}{cc}\mathbf{6} & \mathbf{9} \\ + & + \\ 1: 160 & 1: 160 \\ 1: 80 & 1: 80 \\ + & +\end{array}$

+
$1: 160$

$1: 80$

$+$

+
$1: 320$

$1: 160$

1.160
+

+
$1: 160$

$1: 160$

$1: 80$

$+$

+
$1: 160$

$1: 80$

$+$

$+$

$1: 320$

$1: 80$

1.80
+

$+$

$1: 320$

$1: 160$



+
$1: 320$

$1: 320$

1:160

$+$

9

12 Meses

15
+
$1: 160$

18
+
$1: 160$

\begin{tabular}{|c|c|c|}
\hline 21 & 24 & 27 \\
\hline+ & + & + \\
\hline $1: 160$ & $1: 160$ & $1: 160$ \\
\hline 1:80 & $1: 40$ & $1: 40$ \\
\hline+ & + & + \\
\hline- & - & - \\
\hline $1: 20$ & 0 & 0 \\
\hline 0 & 0 & 0 \\
\hline$+d$ & - & - \\
\hline- & - & - \\
\hline 0 & 0 & 0 \\
\hline 0 & 0 & 0 \\
\hline- & - & - \\
\hline- & - & - \\
\hline 0 & 0 & 0 \\
\hline 0 & 0 & 0 \\
\hline- & - & - \\
\hline+ & + & + \\
\hline $1: 160$ & $1: 160$ & $1: 160$ \\
\hline $1: 20$ & $1: 20$ & $1: 20$ \\
\hline+ & + & + \\
\hline+ & + & + \\
\hline $1: 160$ & $1: 160$ & $1: 160$ \\
\hline $1: 80$ & $1: 80$ & $1: 80$ \\
\hline+ & + & + \\
\hline+ & + & + \\
\hline $1: 160$ & $1: 160$ & $1: 160$ \\
\hline $1: 40$ & $1: 40$ & $1: 40$ \\
\hline+ & + & + \\
\hline
\end{tabular}

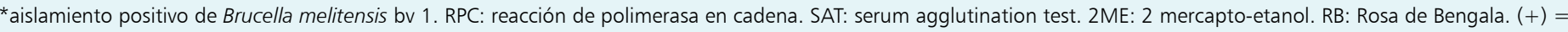
amplificación del producto de 223 pb. $(-)=$ sin producto de amplificación. $+d=$ positivo débil. 
el segundo tratamiento, las pruebas serológicas y la RPC fueron negativas, las que se mantuvieron así hasta el término del seguimiento.

En el caso de la madre de 49 años, portadora de diabetes mellitus tipo 2 (DM 2) que desde hacía 10 años la controlaba con 15 UI de insulina NPH c/24 h, su sintomatología fue muy intensa. Se le indicó inicialmente cotrimoxazol y rifampicina; a los tres meses de haber terminado el tratamiento continuaba principalmente con artralgias que llegaron a incapacitar la deambulación, pero no cursaba con datos clínicos de neuro-infección, por lo que se solicitó interconsulta con Medicina Interna. Le fue indicado el tratamiento de doxiciclina y rifampicina a los 180 días de seguimiento. Sin embargo, después de tres meses de haber concluido el segundo tratamiento, continuaba con intensa cefalea y artralgias. Sus títulos serológicos y la RPC se mantenían positivos. A los 360 días comenzó a tomar el tratamiento de estreptomicina y tetraciclina. Los títulos en las pruebas continuaron positivos aún después del término del tercer tratamiento, 1:160 en SAT y 1:20 en 2ME, y estables hasta el término de este seguimiento, mientras los resultados de la RPC también permanecieron positivos. Presentó finalmente una disminución significativa en la sintomatología al concluir el seguimiento.

La abuela de la familia, de 72 años, también con DM 2, recibía 15 UI de insulina $\mathrm{NPH}$ c/24 h. Al inicio del seguimiento tomó el tratamiento de cotrimoxazol y rifampicina. Completó el tratamiento y, al decir por las palabras de la paciente, tuvo apego al mismo. Fue ingresada al Hospital de Zona No. 25 del IMSS de la Ciudad de México, por presentar artralgias que le ocasionaron limitación en la marcha donde fue manejada por especialistas de Medicina Interna. Los estudios radiológicos indicaron la presencia de sacro-ileítis. No cursaba con datos clínicos de neuroinfección. Los resultados de las pruebas de laboratorio durante su estancia en el hospital fueron serología y RPC positivas. Hospitalizada inició o el tratamiento de doxiciclina y rifampicina; al término de éste sus títulos fueron de 1:60 en SAT, 1:80 en 2ME y RPC positiva. Debido a que a los 15 meses del seguimiento continuaba con síntomas y artralgias se le administró el tratamiento de estreptomicina y tetraciclina. Al término del seguimiento la paciente mejoró su sintomatología y podía caminar sin dolor; no obstante, continuaba con pruebas serológicas y RPC positivas.

El hermano fue uno de los pacientes en quien se aisló B. melitensis bv 1; tomó únicamente el tratamiento con cotrimoxazol y rifampicina por 21 días, al inicio del seguimiento. Este paciente, al igual que el caso índice, decidió no tomar otro tratamiento a pesar de continuar con cefalea y dolores articulares. Se observaron los siguientes títulos al terminar el seguimiento: 1:160 en SAT y 1:40 en $2 \mathrm{ME}$ y RPC positiva.

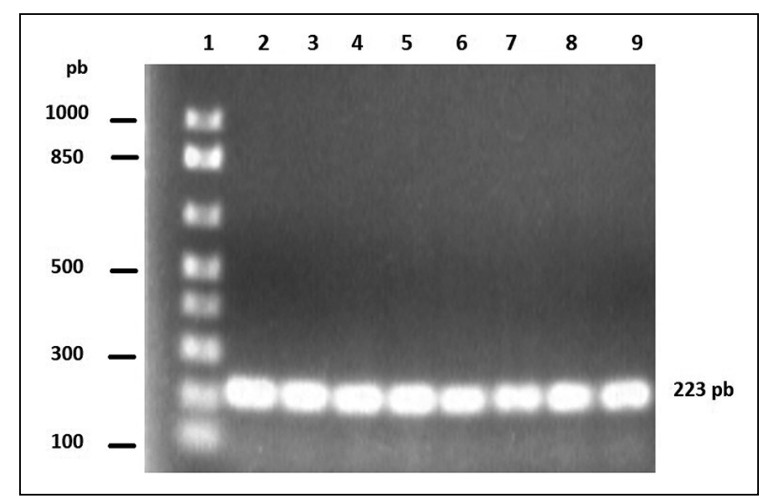

Figura 1. Amplificación del gen bcsp31 por RPC en el suero de pacientes al inicio del seguimiento. Carriles: 1) Marcador 1 kb; 2) Caso índice; 3) Padre; 4) Tía; 5) Prima; 6) Madre; 7) Abuela; 8) Hermano y 9) Testigo positivo $B$. melitensis $16 \mathrm{M}$.

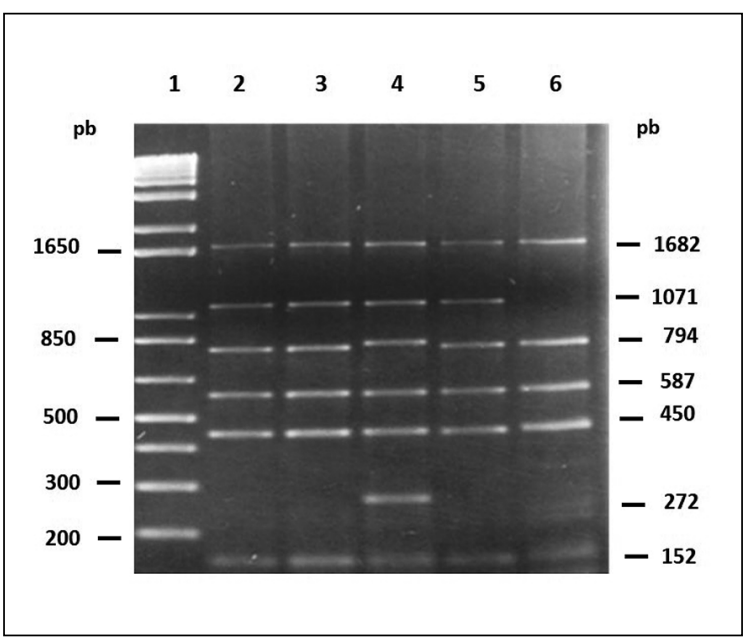

Figura 2. Identificación molecular de las dos cepas aisladas de los pacientes mediante RPC Multiplex Bruce-ladder. Carriles: 1) Marcador $1 \mathrm{~kb}$; 2) Cepa aislada del padre; 3) Cepa aislada del hermano; 4) $B$. suis 1330; 5) B. melitensis 16M; 6) B. abortus 544 .

\section{Discusión}

Las especies del género Brucella son bacterias intracelulares facultativas que, una vez que entran en el hospedero, son fagocitadas por los macrófagos donde son capaces no sólo de sobrevivir sino de mantener una residencia prolongada dentro del compartimento fagosomal ${ }^{19}$. Estas características tan particulares del patógeno definen la infección en el humano, que sin un diagnóstico y sin una terapia adecuada podría evolucionar a una brucelosis crónica. Una de las problemáticas en el establecimiento del diagnóstico es el amplio espectro de las manifestaciones clínicas. La brucelosis se presenta con síntomas similares a otras infeccione febriles por lo que el médico podría llegar a establecer un diagnóstico erróneo y recetar un tratamiento que no eliminaría a Brucella ${ }^{5}$. El historial de los pacientes mostró que todos ellos recibieron diagnósticos y tratamientos erróneos, inadecuados para eliminar la brucela. La familia vivía en la zona urbana de Ciudad de México, donde los médicos familiares generales no tienen experiencia en el diagnóstico de brucelosis. 
En países endémicos, las autoridades de Salud Pública deberían concientizar a los médicos sobre la importancia de la brucelosis en la población humana. Como sucedió con esta familia, la población en general puede estar en riesgo de adquirir la enfermedad a través del consumo de derivados lácteos no pasteurizados provenientes de zonas endémicas de brucelosis. En la literatura se reportan casos de brucelosis en viajeros que visitaron países endémicos o en inmigrantes, que transportaron los derivados lácteos sin pasteurizar, a países libres de brucelosis ${ }^{20-22}$.

Las pruebas serológicas son de manera práctica las más utilizadas en el diagnóstico de brucelosis en el humano. Los títulos de anticuerpos usualmente disminuyen después de iniciar un tratamiento específico contra Brucella; por ello, el seguimiento serológico del paciente se recomienda con el fin de observar la respuesta hacia el tratamiento. Sin embargo, se ha reportado que la presencia de títulos elevados de anticuerpos anti-Brucella podría persistir por meses o aún por años en los pacientes después de un tratamiento efectivo, en ausencia de sintomatología y con cultivo negativo en sangre, es decir clínicamente sanos ${ }^{23}$.

El seguimiento serológico de los integrantes de la familia se basó en tres pruebas serológicas, establecidas por la NOM-022-SSA2-2012 y aceptadas internacionalmente $^{12,13}$. Al inicio del seguimiento todos los pacientes presentaron una brucelosis activa (títulos serológicos entre 1:640 y 1:320). El caso índice y su hermano presentaron disminución en sus títulos iniciales después de concluir el tratamiento con cotrimoxazol y rifampicina. Un mes después manifestaron cefalea, artralgias y lumbalgia, con aumento en los títulos de serología, lo cual indicaba que el tratamiento no había sido satisfactorio. Por lo que se les prescribió un nuevo tratamiento que ninguno de los dos pacientes quiso seguir. Los tratamientos prolongados y la baja tolerabilidad de algunos antimicrobianos dificultan la adherencia en esta afección. Es importante concientizar a los pacientes de la importancia de concluir el tratamiento para poder eliminar a la bacteria.

Con la finalidad de confirmar la presencia de Brucella se les realizó hemocultivo a los seis meses y otro a los nueve meses del seguimiento, los que fueron negativos. Por la duración de la sintomatología descrita en el caso índice y su hermano, ambos se consideran clínicamente crónicos, al finalizar este seguimiento. Cabe mencionar que ninguno de los dos presentó complicaciones viscerales.

Por otra parte, el padre, tía y prima, tuvieron una recuperación total de la brucelosis, habiendo recibido durante nueve meses dos diferentes esquemas; al término del primero (cotrimoxazol y rifampicina), sus títulos serológicos y RPC aún eran positivos, presentaban cefalea, artralgia, lumbalgia, y cansancio. Posteriormente se les indicó doxiciclina y rifampicina con los que sus títulos de serología disminuyeron hasta negativizarse al final del seguimiento.
Dos casos muy difíciles de manejar fueron los de la madre y la abuela, debido a que ambas tenían DM 2 diagnosticada hacía más de 10 años. Las dos pacientes presentaron una sintomatología muy agresiva en comparación con los demás familiares, probablemente debido a su afección diabética. En ambos casos, los tratamientos no fueron satisfactorios, seguían presentando la sintomatología, los títulos de anticuerpos no disminuyeron y la RPC permanecía positiva. La madre recibió tres diferentes esquemas antimicrobianos y continuaba con fuerte cefalea. Mientras que la abuela, tuvo que ser hospitalizada por complicaciones osteo-articulares. Algunos autores proponen que la diabetes mellitus genera una respuesta inmune innata defectuosa que hace más susceptibles a los diabéticos a las infecciones bacterianas. Parte de la evidencia que soporta esta hipótesis es que células mononucleares de sangre periférica y monocitos de pacientes con DM 2 que mostraban un pobre control glicémico, fueron defectuosos en producir IL-12 en respuesta a Burkholderia pseudomallei y Mycobacterium tuberculosis. El defecto en la producción de IL-12 afectó en consecuencia la producción de IFN- $\gamma$ y la actividad bactericida de los monocitos contra estas bacterias intracelulares ${ }^{24}$. En el caso de Brucella, se ha reportado que ratas Wistar a las que se les indujo la diabetes mediante estreptozotocina, presentaron una infección más grave por $B$. melitensis que el grupo de ratas no diabéticas ${ }^{25}$. Más recientemente, se reportó que $B$. abortus tiene preferencia de sobrevivir y replicarse dentro de un cierto tipo de macrófagos (1lamados macrófagos activados alternativamente, AAMs) durante el estado crónico de la infección en ratón. Además se encontró que $B$. abortus aumentaba su sobrevivencia dentro de este tipo de macrófagos cuando había mayor disponibilidad de glucosa intracelular mediada por un shift metabólico inducido por los receptores gamma activados por los proliferadores peroxisomales (PPAR $\gamma$ ). La entrada de glucosa fue crucial para incrementar la replicación de Brucella y mantener la infección crónica en los ratones ${ }^{26}$. Dada la compleja etiología de la DM2 y sus múltiples complicaciones asociadas, los mecanismos subyacentes entre la asociación de la diabetes y las infecciones bacterianas han sido poco estudiados. Pocos reportes de casos de pacientes diabéticos infectados con brucelosis se encuentran en la literatura médica, siendo la diabetes la tercera causa de muerte en países de Latinoamérica. Por lo que es importante publicar los casos de diabéticos con brucelosis para obtener mayor información sobre el tratamiento y manejo clínico de este tipo de pacientes.

Las cepas de Brucella son susceptibles a varios antimicrobianos in vitro; sin embargo, pocos de ellos son efectivos in vivo, por ello el tratamiento contra brucelosis requiere de fármacos que muestren una buena penetración intracelular ${ }^{27}$. La localización intracelular del patógeno le brinda no sólo protección contra los antimicrobianos sino 
que además, la naturaleza ácida de la vacuola fagocítica puede disminuir la efectividad de ciertos tipos de fármacos como son los macrólidos ${ }^{28}$.

Recientemente se han publicado meta-análisis con la finalidad de evaluar diferentes tratamientos contra brucelosis humana ${ }^{29,30}$. Sus resultados mostraron que el tratamiento con doxiciclina y rifampicina durante seis semanas mostró ligeramente menos recaídas y persistencia de síntomas que doxiciclina por seis semanas más estreptomicina por 2 ó 3 semanas $^{30}$. Mientras, que Solís y Solera concluyeron que la combinación de doxiciclina y estreptomicina fue superior (en términos del porcentaje de recaídas o falla terapéutica) en comparación con doxiciclina y rifampicina. A pesar de que doxiciclina más estreptomicina se posiciona como el tratamiento de primera elección, la vía parental de los aminoglucósidos podría complicar el uso de este tratamiento; los profesionales de la salud prefieren el uso de doxiciclina y rifampicina ${ }^{29}$. Por otro lado, el estudio de meta-análisis no mostró diferencia significativa cuando se comparó el tratamiento con doxiciclina más rifampicina versus quinolonas (ofloxacina o ciprofloxacina) más rifampicina en términos de falla terapéutica ${ }^{29,30}$. Sin embargo, los autores mencionan que existe poca evidencia que soporte actualmente la utilidad de las quinolonas en el tratamiento. A pesar de que varios reportes mencionan que la monoterapia en el tratamiento de brucelosis se asocia con un alto porcentaje de recaídas (en el caso de tetraciclina), Solís y Solera proponen que el uso de doxiciclina como monoterapia no debería descartarse y que se requiere mayor investigación al respecto $^{29}$. Además, tomando en cuenta los datos actuales, las terapias basadas en el uso de tres antimicrobianos no se recomiendan; se requiere mayor información que soporte este tipo de tratamiento ${ }^{30}$.

Otro aspecto importante en cuanto al tratamiento de brucelosis es el costo de los antimicrobianos, que deberá tomarse en cuenta, sobre todo en países en vías de desarrollo. Según lo reportado por Straight y Martin, cotrimoxazol fue el antimicrobiano más barato, seguido de doxiciclina, mientras que las quinolonas fueron las más costosas. La combinación terapéutica más económica fue doxiciclina y cotrimoxazol ${ }^{31}$. Es importante mencionar que el meta-análisis de Yousefi-Nooraie y cols., se limitó a pacientes adultos con brucelosis por lo que los hallazgos no son aplicables a niños, mujeres embarazadas o pacientes con complicaciones como espondilitis $\mathrm{y}$ neurobrucelosis ${ }^{30}$.

Se ha reportado que la brucelosis y la tuberculosis, segunda causa de muerte en el mundo, co-existen en las mismas comunidades; en ambas enfermedades, tanto rifampicina como estreptomicina se usan en el tratamiento. El uso extensivo de ambos antimicrobianos para el tratamiento contra brucelosis podría generar resistencia en las micobacterias por lo que ya no serían efectivos en casos de tuberculosis. Ésta es una problemática que los epidemiólogos tendrán que tomar en cuenta en el tratamiento de casos humanos en zonas endémicas de brucelosis y tuberculosis ${ }^{32}$.

Los antimicrobianos, suministrados a los pacientes de este seguimiento, fueron la combinación de dos antimicrobianos recomendados por OMS desde 1986, y establecidos por NOM-022-SSA2-2012. En nuestro reporte, el padre, la tía y la prima, quienes tomaron doxiciclina y rifampicina como segunda terapia mostraron resultados negativos en serología y RPC al final del seguimiento. Resultados parecidos fueron reportados por Buzgan y cols., en pacientes con complicaciones ostearticulare ${ }^{33}$, en contraste con los hallazgos de otros autores quienes reportaron que esta combinación fue la menos efectiva en el tratamiento de casos humanos ${ }^{34,35}$. En los casos de las pacientes con DM2 no mostraron mejoría después del tratamiento con doxiciclina y rifampicina. Estas pacientes a pesar de haber concluido tres tratamientos antimicrobianos, continuaron con sintomatología, serología y RPC positivas. En ambos casos se podría considerar un tratamiento alternativo, por ejemplo la combinación de quinolonas y rifampicina bajo estricta supervisión médica ${ }^{29}$.

La RPC se ha utilizado también en el diagnóstico de brucelosis tanto en humanos como en animales; es más específica que las pruebas serológicas rutinarias y es sensible ${ }^{36}$. En virtud de sus características, se ha mostrado como una prueba de diagnóstico alternativa al cultivo microbiológico y además se aplica en la identificación de Brucella directamente de muestras como tejidos, orina, sangre, suero, leche, queso, o cultivos puros ${ }^{16}$. A la fecha, la RPC es útil en el diagnóstico de pacientes con brucelosis aguda, como lo observaron Vrioni y cols. Sin embargo, ellos también observaron que de 39 pacientes, $87 \%$ seguían teniendo RPC positiva al final de tratamiento, en $77 \%$ permanecía positiva después de 6 meses del tratamiento mientras que $70 \%$ permaneció positivo al RPC aún después de 2 años; ninguno de los pacientes mostró sintomatología de recaídas ${ }^{37}$.

Al inicio de este seguimiento, todos los pacientes tuvieron RPC positiva, mientras que al final sólo aquellos asintomáticos y con serología negativa tuvieron resultados de RPC negativos (el padre, la tía, y la prima). En el caso de las pacientes diabéticas y los dos pacientes que tomaron un solo tratamiento, los resultados de RPC continuaron positivos hasta el final del seguimiento.

Ya anteriormente, otros autores habían reportado que un número significativo de pacientes presentaron evidencia de la presencia de la bacteria (ya fuese a través de anticuerpos o por la presencia de $\mathrm{ADN}$ ) aún años después de tener una cura clínica y en ausencia de síntomas que indicaran persistencia de la enfermedad o una recaída. Es probable que las bacterias (posiblemente en un bajo número) no sean capaces de generar una manifestación clínica 
clara, posiblemente debido a que la respuesta inmune es lo bastante robusta y sostenida que eventualmente elimine a la bacteria. A pesar de que la RPC es una prueba con una sensibilidad alta, un resultado de RPC negativo no excluye la presencia de la enfermedad, específicamente en los inicios de la infección ${ }^{38-40}$. Además, la presencia de la bacteria en sangre es transitoria, y en otros fluidos la bacteria podría simplemente no estar presente en un número suficiente que permitiera ser detecta en el momento del análisis. Por otro lado, la presencia de ADN detectable mediante RPC no necesariamente prueba la viabilidad bacteriana ni que la enfermedad esté activa ${ }^{37}$. A pesar de que la RPC es una técnica con un gran valor diagnóstico, la estandarización de la preparación de la muestra, el método de extracción de ADN así como la elección de la secuencia genética a ser amplificada influyen en la interpretación de los resultados. Por ello, es importante que se establezcan protocolos estandarizados que permitan la comparación de los resultados en diferentes laboratorios. La RPC deberá entonces ser interpretada en el contexto clínico y bajo el conocimiento de sus limitaciones de la técnica9 9

\section{Conclusiones}

Tanto las pruebas serológicas como la RPC fueron útiles en el seguimiento de los pacientes con brucelosis. La RPC es una prueba con un valor diagnóstico pero que también tiene ciertas limitaciones que deberán tomarse en cuenta en la interpretación de los resultados. Se recomienda el seguimiento clínico de pacientes con brucelosis durante más de seis meses para evaluar el tratamiento y las recaídas. Los pacientes con persistencia de síntomas, serología y RPC positivas después de haber concluido el primer tratamiento deberán ser monitoreados y discutirse el uso de un segundo tratamiento. El reporte de casos de diabéticos que contrajeron brucelosis es muy valioso, lo que ayudará a tener mayor información sobre el manejo de este tipo de pacientes. Finalmente, recomendamos al personal médico actualizarse en los reportes relacionados con el tratamiento de brucelosis, especialmente en casos con complicaciones.
Agradecimientos. MRMG recibió beca de COTEPABE/ PL/270/1O-IPN, COTEBAL/PL/23/12-IPN and COTEBAL/ PL/41/12-IPN. ACR, y ALM recibieron beca de COFAAIPN, EDI-IPN and SNI-CONACYT. ACR recibió semestre sabático agosto de 2013-enero de 2014 ENCB-IPN. Al Ing. Aaron de la Vega Lara por su valioso apoyo técnico. Al QBP Roberto Migrañas Ortiz por donar los reactivos para las pruebas serológicas. En especial agradecimiento a cada uno de los integrantes de la familia que autorizaron la divulgación de los resultados de este seguimiento.

\section{Resumen}

Introducción: El diagnóstico de brucelosis humana es difícil pues los cultivos de sangre y tejidos tienen un rendimiento limitado (40-70\%) y usualmente se recurre a la serología como recurso complementario; últimamente se han desarrollado técnicas de biología molecular que intentan optimizar la confirmación etiológica. Objetivo: Comparar la reacción de la polimerasa en cadena (RPC) con las pruebas de diagnóstico serológicas en el seguimiento clínico de una familia con brucelosis. Métodos: Siete integrantes de una familia con brucelosis que habitaban la zona urbana de Ciudad de México fueron monitoreados mediante aglutinación con antígeno Rosa de Bengala, prueba de aglutinación, aglutinación en presencia de 2 mercapto-etanol, hemocultivos y RPC en suero durante 27 meses. La probable fuente de infección de los pacientes fue el consumo de queso fresco de cabra originario de una zona endémica. Resultados: Brucella melitensis se obtuvo del hemocultivo de dos pacientes. Todos los pacientes fueron positivos a las pruebas serológicas y al RPC al inicio del seguimiento. Tres pacientes respondieron bien al tratamiento y mostraron resultados negativos en serología y RPC al final del estudio. Mientras que en dos pacientes con diabetes mellitus tipo 2 la sintomatología fue persistente, serología positiva y RPC positivos al finalizar el estudio. Conclusión: El seguimiento clínico de pacientes con brucelosis es muy importante para valorar el tratamiento, en este sentido la RPC es una herramienta que puede apoyar a otras pruebas de diagnóstico.

\section{Referencias bibliográficas}

1.- Pappas G, Papadimitriou P, Akritidis N, Christou L, Tsianos E V. The new global map of human brucellosis. Lancet Infec Dis 2006; 6: 91-9.

2.- Godfroid J, Cloeckaert A, Liautard J P, Kohler S, Fretin D, Walravens K. From the discovery of the Malta fever's agent to the discovery of a marine mammal reservoir, brucellosis has continuously been a re-emerging zoonosis. Vet Res 2005; 36: 313-26.

3.- Álvarez J, Sáez J L, García N, Serrat C, Pérez-Sancho M, González S, et al. Management of an outbreak of brucellosis due to $B$. melitensis in dairy cattle in Spain. Res Vet Sci 2011; 90: 208-11.

4.- Corbel M J. Brucellosis in humans and animals. WHO Library Cataloguing-in-Publication Data. 2006. Chapter 2. Epidemiology 14-5.

5.- Corbel M J. Brucellosis in humans and animals. WHO Library Cataloguing-in-Publication Data.
2006.Chapter 2. Clinical manifestation 6-9.

6.- Baldwin C L, Goenka R. Host immune response to the intracellular bacteria Brucella: does the bacteria instruct the host to facilitate chronic infection? Crit Rev Immunol 2006; 26: 407-12.

7.- Corbel M J. Brucellosis: an overview. Emerg Infect Dis 1997; 3: 213-21.

8.- Ruiz-Mesa J D, Sánchez-González J M, Martín L, López-Palmero S, Colmenero J D. Rose Bengal test: diagnostic yield and use for the rapid diagnosis of human brucellosis in 
emergency departments in endemics areas.

Clin Microbiol Infect 2005; 11: 221-5.

9.- Navarro E, Casao M A, Solera J. Diagnosis of human brucellosis using PCR. Expert Rev Mol Diagn 2004; 4: 115-23.

10.- Mitka S, Anetakis C, Souliou E, Diza E, Kansouzidou A. Evaluation of different PCR assays for early detection of acute and relapsing brucellosis in humans in comparison with conventional methods. J ClinMicrobiol 2007; 45: 1211-8.

11.- Casañas M C, Quiepo-Ortuño M I, Rodríguez-Torres A, Orduña A, Colmenero J D, Morata P. Specificity of polymerase chain reaction assay of a target sequence on the 31-Kilodalton Brucella antigen DNA used to diagnose human brucellosis. Eur J Clin Microbiol Infect Dis 2001; 20: 127-31.

12.- DOF. Diario Oficial de la Federación, 14 de marzo de 2012. NOM-022-SSA2-2012. Para la prevención y control de la brucelosis en el hombre, en el primer nivel de atención. Disponible: DOF: 11/07/2012 NOM-022-2012Brucelosishumana (accedido el 31 de enero de 2014).

13.- Al Dahouk S, Tomaso H, Nöckler K, Neubauer H, Frangoulidis D. Laboratory based diagnosis of brucellosis a review of the literature. Part II: serological tests for brucellosis. Clin Lab 2003; 49: 577-89.

14.- Alton G G, Jones L M, Angus R D, Verger J M. Techniques for the Brucellosis Laboratory. Paris: Institut National de la Recherche Agronomique, First edition 1988. (Paris).

15.- Baily G G, Krahn J B, Drasar B S, Stoker N G. Detection of Brucella melitensis and Brucella abortus by DNA amplification. J Trop Med Hyg 1992; 95: 271-5.

16.- Al Dahouk S, Tomaso H, Nöckler K, Neubauer H, Frangoulidis D. Laboratory based diagnosis of brucellosis a review of the literature. Part I: Techniques for direct detection and identification of Brucella spp. Clin Lab 2003; 49: 487-505.

17.- García-Yoldi D, Marín C M, de Miguel M J, Muñoz P M, Vizmanos J L, López-Goñi I. Multiplex PCR assay for the identification and differentiation of all Brucella species and the vaccine strains Brucella abortus S19 and RB51 and Brucella melitensis. Rev Clin Chem 2006;
52: 779-81.

18.- Morales-Estrada A I, Castillo-Salto J, LópezMerino A, Morales-García M R, Valle-Valdez J G, Contreras-Rodríguez A. Characterization of Brucella species in Mexico by Bruce-Ladder polymerase chain reaction (PCR).

Afr J Microbiol Res 2012; 6: 2793-6.

19.- Kohler S, Layssac M, Naroeni A, Gentschev I, Rittig M, Liautard J P. Secretion of listeriolysin by Brucella suis inhibits its intra macrophagic replication. Infect Immun 2001; 69: 2753-6.

20.- Arnow P M, Smaron M, Ormiste V. Brucellosis in a group of travelers to Spain. JAMA 1984; 251: 505-7.

21.- Memish Z A, Balkhy H H. Brucellosis and international travel. J Travel Med 2004; 11: 49-55.

22.- Tsou T P, Mu J J. Brucellosis: a neglected but existing threat to travelers and laboratory personnel in Taiwan. J Formos Med Assoc 2012; 111: 353-4.

23.- Ariza J, Pellicer T, Pallarés R, Foz A, Gudiol F. Specific antibody profile in human brucellosis. Clin Infect Dis 1992; 14: 131-40.

24.- Gan Y H. Host susceptibility factors to bacterial infections in type 2 diabetes. Plos Pathog 2013; 9: e1003794.

25.- Yumuk Z, Küçükbasmaci O, Büyükbaba Boral O, Küçüker Anğ M, Dundar V. The effects of streptozotocin-induced diabetes on brucellosis of rats. FEMS Immunol Med Microbiol 2003; 39: 275-8.

26.- Xavier M N, Winter M G, Spees A M, den Hartigh A B, Nguyen K, Roux C M, et al. $\operatorname{PPAR} \gamma$ mediated increase inglucose availability sustains chronic Brucella abortus infection in alternatively activated macrophages. Cell Host Microbe 2013;14: 159-70.

27.- Solera J, Martínez-Alfaro E, Espinosa A. Recognition and optimum treatment of brucellosis. Drugs 1997; 53: 245-56.

28.- Solera J, Beato J L, Martínez-Alfaro E, Segura J C, de Tomás E, Grupo de Estudio de Castilla la Mancha de Enfermedades Infecciosas Group. Azithromycin and gentamicin therapy for the treatment of humans with brucellosis. Clin Infect Dis 2001; 32: 506-9.

29.- Solís García del Pozo J, Solera J. Systematic review and meta-analysis of randomized clinical trials in the treatment of human brucellosis. PLoSOne. 2012; 7: e 32090.

30.- Yousefi-Nooraie R, Mortaz-Hejri S, Mehrani M, Sadeghipour P. Antibiotics for treating human brucellosis. Cochrane Database Syst Rev 2012;10:CD007179. doi: 10.1002/14651858. CD007179.pub2.

31.- Straight T M, Martin G J. Brucellosis. Curr Treatment Options Infect Dis 2002; 4: 447-56.

32.- Dasari S, Naha K, Prabhu M. Brucellosis and tuberculosis: clinical overlap and pitfalls. Asian Pac J Trop Med 2013; 6: 823-5.

33.- Buzgan T, Karahocagil M, Irmak H, Baran A I, Karsen H, Evirgen O, et al. Clinical manifestations and complications in 1028 cases of brucellosis a retrospective evaluation and review of the literature. Int J Infect Dis 2010; 14: e469-78.

34.- Parlak M, Güdücüoğlu H, Bayram Y, Çikman A, AypakC, Kiliç S, et al. Identification and determination of antibiotic susceptibilities of Brucella strains isolated from patients in Van, Turkey by conventional and molecular methods. Int J Med Sci 2013; 10: 1406-11.

35.- Safi M, Al-Mariri. Efficacy evaluation of some antibiotics against Brucella spp. isolates, in vitro. Braz J Microbiol 2012; 43: 1269-73.

36.- Queipo-Ortuño M I, Morata P, Ocón P, Manchado P, Colmenero J D. Rapid diagnosis of human brucellosis by peripheralblood PCR assay. J Clin Microbiol 1997; 35: 2927-30.

37.- Vrioni G, Pappas G, Priavali E, Gartzonika C, Levidiotou S. An eternal microbe: Brucella DNA load persists for years after clinical cure. Clin Infec Dis 2008; 46: e131-6.

38.- Al-Attas RA, Al-Khalifa M, Al-Qurashi A R, Badawi M, Al-Gualy. Evaluation of PCR, culture and serology for the diagnosis of acute human brucellosis. Ann. Saudi Med 2000; 20: 224-8.

39.- Nimri L F. Diagnosis of recent and relapsed cases of human brucellosis by PCR assay. BMC Infect Dis 2003; 28: 3-5.

40.- Morata P, Queipo-Ortuño M I, Reguera J M, García-Ordoñez M A, Pichardo C, Colmenero J D. Post treatment follow-Up of brucellosis by PCR assay. J Clin Microbiol 1999; 37: 4163-6. 